\title{
Sustainable Development Goals and Media Coverage by English Language News Channel Websites in Indian and International Context
}

\author{
Swamini Pandit
}

\begin{abstract}
Environmental sustainability should be the highest priority of each new generation. A toxic-free future can only be achieved if the goal of environmental sustainability, clean production, improved health and democratic decision making for the entire human race are at the core of policy making. The Brundland Commission established by the World Commission on Environment and Development in year 1987, gave equal value to economic growth, social progress, ecological health, and, in more recent interpretations, cultural and informational sustainability. But, mainstream approaches to green governance of environmental protections are mostly human centred and focus on saving lives, infra structure and heritage from environmental risks. [1]
\end{abstract}

At this juncture, the role of mass media becomes pertinent as it can play a vital role in awakening people about recent trends and developments for protection and preservation of environment and ultimately meeting the SDGs (Sustainable Development Goals).

Where the Mass Media relies on mono-directional communication, the modern media namely social media is more interactive and involves webs of communications. This form of communication is effective in sharing or expressing opinions or even expressing alternate and opposing views on current issues. This emerging form of media is strengthening the role of media as the watchdog for democracy in this era [2]. Considering the role that media websites can play in enhancing the awareness, triggering the discussions and subsequently accelerating public participation in meeting the SDGs, I found the medium of news channel websites more appropriate for this study. This paper analyses the coverage of topic 'SDGs' in four leading news channel websites.

This is a qualitative analysis to figure out the extent of coverage of the topic 'SDGs' both at National and International level through these websites. The secondary literature review method is used for this paper. Content survey of news channel websites and research work through internet are the sources of this study.

Keywords: Media, News channel websites, Sustainable Development Goals

\section{INTRODUCTION}

The challenges of sustainable development cannot be addressed by governments and agencies working in isolation and it calls for a joint effort and action by all the actors facing a common future. With this view all the United Nation Member states adopted the Sustainable Development Goals (SDGs), also known as the Global Goals, with aim of creating a common program to uplift the societies riddled with chronic poverty, protect the planet from the effects of global warming and ensure that everyone of us enjoy peace and prosperity by the year 2030 .

Revised Manuscript Received on February 06, 2020.

Swamini Pandit*, Freelance Language faculty, Pune, India.

panditswamini@gmail.com
Environmental sustainability rests on "non negotiable planetary preconditions" (Rockstrom et al. 2009: 4). Economic, social and cultural activities rely on the resources that earth provides. However there is a finite limit on how much the Earth can give to and absorb from these activities [1]. Today's development challenges stemming from climate crisis to rising inequalities and protracted conflict require a uniform approach. The way countries work and the solutions they develop must be integrated.

The 2030 Agenda for Sustainable Development sets forth seventeen Sustainable Development Goals (SDGs), encompassing the social, economic and environmental aspects of development. The purpose of these goals is to enable countries to respond to many intricate challenges.

To address the complex development challenges, UNDP introduced SDG integration which is based on systems approach. The focus is on promoting learning to help countries reach their development goals. MAPS which stands for (Mainstreaming, Acceleration, and Policy Support), was adopted by UNDP and fellow UN agencies. Using this approach these agencies supported 97 projects in 38 countries. MAPS help countries to line up planning and budgeting processes in order to shift the goals from commitments to action.

As part of the UN Development System, UNDP has put in place the following four dedicated streams of work,

\section{$>$ Innovation and Learning \\ $>$ Data and Analytics \\ $>$ Financing \\ $>$ Nextgen Policy}

The objective of these work streams is to support countries to design policy and programmes for the future, access and generate finance, source and analyse data, and drive innovation and learning. The focus is not on individual goals but to identify the missing pieces that make the whole of Agenda 2030 possible. The work streams will help to fill the gaps between these individual goals. [3]

It is important now, more than ever, to address the concern for environment and adopt SD as an agenda of the country, at both the macro and micro level. Mass media is a significant source to carry this message across. To get a clearer perspective of where the country stands in examining the essentials of the environment it is important to know the way mass media, especially news media reflects environment in their coverage [4].

With the rapid innovations in the communication technology, its ease of accessibility to the masses coupled with increasing economic pressures there is a significant change in the roles, operations and practices of news media and news professionals in the last decades [5]. 
TV channels, particularly round-the-clock news channels, now have an increased reach and through the talk shows, discussion forums they are becoming the agenda setters and path makers for public policies and priorities. There have been major developments in the last decade with regard to climate change. The vantage point that the news channel have and the increased role that they have assumed in shaping the opinion of the masses raise hopes that the media will take up more coverage of environment in a more influential way.

The content that gets priority on the news channels is predominantly TRP driven. Hence typically it is politics, entertainment, sports and crime that gets prime concern of news channels. It is observed that any deviation is infrequent or temporal. Shift in the focus towards the coverage of environment concerns will be a real step forward but unlikely to happen until TRP-driven content priorities are followed [4].

This paper tries to find the extent and scope of coverage by news media of the topic 'SDG' in particular. Among the various media sources ranging from print, audio or even social, News channel websites are chosen to analyse my assumption that Indian media is not very prominent in highlighting the area of Sustainable Development. Hence it is compared with International media. News channel websites are widely viewed by people of all age groups, and are easily accessible to those having a smart phone, which means most of the world population. This is considered as a quick and authentic way of being in touch with the world's important happenings just on a finger click. There are numerous English language News channels' websites worldwide. In this article, the focus is particularly on English language websites because of their reach across the continents and also for the ability to search news specific to the keyword 'Sustainable Development Goals'.

As a literature review, some research papers were studied in which the Media in India, in particular, news paper media and TV news channels (at their prime time) and Environmental issues are linked. These papers use the quantitative analysis method and come up with the results which show which media has how much coverage of Environment as a whole. The topic of SDG as a core and media was not much found in the search except a report which is published by UNDP. In this, an extensive mapping was conducted to identify promising practices and broader trends in UNDP's work with the media. It identified more than 200 UNDP media-related activities, most of which were undertaken in the years 2016-2018. But, here also, radio, TV and films are the key media sources which are used to promote media literacy in some developing countries. One more research paper titled 'El Ambiente y Las Noticias: Understanding U.S. Spanish- Language Newsrooms' Coverage of Environmental Issues' was studied in which the authors analyse the nature and content of environmental news and the models used by decision makers in Spanish-language newsrooms covering environmental affairs at major U.S. Spanish-language television stations [6].

Since the coverage of SDGs and related progress through media has not been much analysed in the reports found, this study was undertaken.

\section{METHODOLOGY}

A. An Overview of a Period: September, 2015September, 2019

The sole intention of selecting this period for my study is that, the world has been given a new target year to achieve the SDGs in 2015. In 2015 January, the UN General Assembly started with the process of negotiation on the post-2015 development agenda. The process resulted in the successive adoption of the 2030 Agenda for Sustainable Development, with 17 SDGs at its mainstay, at the UN Sustainable Development Summit in September 2015.

2015 was a milestone year for multilateralism and also for international policy shaping, as several major agreements were adopted like:

- Sendai Framework for Disaster Risk Reduction (March 2015)

- Addis Ababa Action Agenda on Financing for Development (July 2015) [7]

- Paris Agreement on Climate Change (December 2015) Hence, the time span of these 4 years is chosen to study the role of News media in conveying the unbiased news about SDGs worldwide.

\section{B. Selection of News Websites}

While selecting the news channel websites, the main parameters were: Popularity, empirically neutral and unbiased nature and impartial broadcast. There are many websites which rank the News channel websites based on such criteria. Therefore, these key words were searched on various internet search engines. To mention fewhttps://blog.feedspot.com, https://www.techworm.net, https://www.makeuseof.com, https://www.forbes.com, http://www.allrefer.com etc. were reffered. Some online forums like https://www.quora.com were also taken into account.

As an outcome of this search, several websites (both Indian and international) came across. To name some of them: BBC News, Fox news, CNN, Sky News, C-Span, Wall Street Journal, Cristian Science Monitor, Pew Research, Reuters, The Associated Press, NPR, Al Jazeera, Euro News, Geo News etc. are among the international sphere. Whereas, popular and authentic Indian news channel websites could be enlisted as: NDTV, CNN-18, Zee News, ABP news, DD News, BBC Worldwide India Pvt Ltd, Independent News Service Pvt. Ltd (India TV), TV Today Network Ltd (AajTak) etc.

Moreover, the major organisations working in the field of Environmental Journalism like 'Society of Environmental Journalists', 'Environmental Media Association (EMA)' and 'Earth Journalism Network' were reffered to further investigate about these websites.

In order to study the news coverage on Sustainable Development Goals, four websites are chosen based on the references found, in which BBC and Al Jazeera are the ones based in UK and Qatar respectively whereas NDTV and CNN-18 are the Indian news channel websites.

\section{Qualitative analysis}

This paper uses the qualitative method to study and analyse how the topic of 'SDG' is covered in news media nationally and internationally. 
For this survey, all the four websites which are mentioned above are studied for the period of 2015-2019. The keyword 'Sustainable Development Goals' was searched to identify the relevant news. Then, the selected news articles were analysed based on the themes and broader trends in which this topic was covered. Here, the content of news is taken into account more than its count.

\section{ANALYSIS OF NEWS CHANNEL WEBSITES}

\section{A. BBC News}

The following observations can be noted after analysing approximately 45 news articles which resulted out of the search.

- Chronologically, most of the articles are from year 2015 when the new agenda was approved by UN. The stories covered include: The reactions of political parties, priority building by the third world countries, campaigns/ rallies/ marches or public reaction in general and a chance given to nations to reform insurance to help those are most at risk from climate change impacts.

- Most of the news is referred to non-developed especially African countries. It checks, where these countries stand at the global agenda. Rather, it highlights that they are way behind in coping up with the lack of education. In news of September 2017, a UN agency has said that, "there has been "nearly zero progress" in tackling the problem of lack of access to the school in world's many poorest countries [8]. ' According to the UN's calculation, 69 million more teachers are to be recruited to meet international education promises for 2030. Whereas, news article from July 2019 shows that, 'across the world, the UNESCO report says, by 2030 about $90 \%$ of adults will be literate. But in some low-income countries, there will still be $30 \%$ of adults who are predicted to be illiterate [9]. Education is the prime theme covered in the span of 201519.

- Poverty, Food scarcity and Health are the next most pronounced stories by BBC while talking about UN global goals. In one of the news, it says that - Millions who are yet left behind in the struggle to combat poverty will not be taken out of it just by economic growth but there are many other factors like instability, weak governance, proneness to disasters, discrimination of various kinds and corruption that can make it really hard to break out severe poverty [10]. Once again, the poor countries from Africa and to some extent India and China were in the coverage while dealing with this issue. On the similar lines, news also covered the findings which are published in the UN Food and Agriculture Organization's (FAO) State of the World's Forests (Sofo), a biennial report that provides data to help inform policymakers and decision-makers. In addition to this, UN states that 'Forests and agriculture have an massive role in achieving the 2030 Agenda's notable commitment to rid the world of the twin challenges of poverty and hunger.'

- It is observed that, Climate change, Biodiversity degradation, Habitat loss, Wildlife or in general Environmental related topics which relate directly to SDGs are comparatively lesser in the coverage. But, news dated $6^{\text {th }}$ May, 2019 extracts the key messages of the most comprehensive and detailed review of the state of nature that has been published in Paris.

Apart from the news articles, BBC has a noticeable initiative that is -'Environmental Sustainability Strategy', where Greener Broadcasting is the approach. Their aim is that- all the informed and engaged employees must work in lowcarbon and efficient environments. Also they must be using minimum resources, producing minimum waste and should travel only when needed [11].

\section{B. Al Jazeera (AJ)}

The channel was found to broadcast nearly 19 news articles by relevance which are analysed as follows.

- Majority of the news articles give the political perspective on SDGs, mainly in the year 2015 after the UN meet. Predominantly it covers the opinions or speeches given over the declaration of 2030 Global Goals. For example, 1. Obama's warning to the world leaders that they will not meet new UN anti-poverty targets without tackling corruption and ending discrimination against women, gays and other marginalised groups [12]. 2. The speech of Pope Francis at the United Nations, UN Headquarters, which emphasises that Economic and social exclusion is a complete denial of human fraternity and a grave offence against human rights and the environment.

- At the same time, it also reveals the expressions of some politician about the current scenario of Global goals and climate change. For ex. The case of Bolivia's President Evo Morales, who said that the countries that were not working to reduce emissions were going against the laws of nature. Also he blamed capitalism for climate change and called on industrialised nations to reduce emissions [13]. These kinds of comments are openly broadcasted by AJ.

- To some extent the channel focuses the news from Syria, Iran or similar war suffered countries and their issues while trying to meet the SDGs.

- Education and poverty concerns from African countries are also the notable topics which have been covered.

- In the year 2018 and 19, more news related to environment are supported. Various topics are incorporated in that, such as:

o Deforestation in the Solomon Islands' tropical forests in an unsustainable rate to meet surging demand for timber from China.

- World's first Sustainable Blue Economy Conference hosted by Nairobi, a summit focusing on how countries can benefit from a "blue economy" which means that, the countries should use oceans and seas to their full advantage without that leading to the suffering of aquatic life, pollution or other negative effects [14].

$\circ$ The threat of food waste to climate change and biodiversity: the recent news says that food waste is presently generating eight percent of greenhouse gas emissions. Hence waste and food loss is a "critical tool" for nations in the battle to tackle climate change.

- Similarly, Food wastage aggravates the negative externalities which agricultural expansions and Monocropping into natural areas create on biodiversity loss [15]. 
- Besides deforestation, growing foods that will never be consumed, fish farming wastes and agricultural runoff are the reasons to create dead zones in many aquatic ecosystems [15].

Other than news articles, AJ works with different components such as AJ Impact and the show Planet SOS which pronounces on the current happenings in a very effective manner which impacts the viewers to a very big extent. Al Jazeera telecasts one environmental show called 'Planet SOS'. It explores various issues like climate also nature and pollution that form the crisis which is being faced by the planet [16]. But, 'news' being on the agenda of this paper, these components are not much taken into consideration.

\section{NDTV India}

This channel was observed to report almost 57 news articles related to the topic of SDGs. Though all the news articles are in Indian context, some different themes are covered in these 4 years' span. The following key points could be noted from the analysis.

- 2015 and 2018 are the years in which the news coverage related to SDGs is predominant. In the two articles of 2015, Nobel laureate Kailash Satyarthi made a strong call to world leaders to give priority to child-related Sustainable Development Goals in their national legislation. "If slavery, trafficking, child labour and violence against children continues, we will fail to accomplish most of the development goals," [17] he said in his address to the UN Summit on SDGs. This is a very essential and remarkable point which he put forth. But neither BBC nor AJ mentioned about this.

- Many among the 2016 news articles take a review of India's rank in the global scenario to achieve SDGs. At that time India was ranked a low 110 out of 149 nations assessed on where they stand with regard to achieving the Sustainable Development Goals, according to a new index.[18] Similarly, a global study on a range of health indicators ranked India 143rd among 188 countries, citing various challenges, including mortality rates, malaria hygiene and air pollution. In the same year, UNESCO's new Global Education Monitoring (GEM) report stated that, 'India could be half a century late in achieving its global education commitments and the country needs fundamental changes in the education system if it wants to meet the 2030 SDGs.' [19]

- Surprisingly, not single news relevant to the topic of SDG was covered by NDTV in year 2017.

- Just the next year (2018), India was referred as a "very important player" [20] of the multilateral system by UN General Assembly (UNGA) President Maria Fernanda Espinosa. When Ms Espinosa had visited India and she had held several meetings with Prime Minister Narendra Modi. While recalling her visit to India, she said she was touched to see how the SDGs were being implemented on the ground in the country [20].

- End of the 2018 and beginning of 2019, major news coverage was about the India- Japan financial deal. Both the countries exchanged notes and signed loan agreements worth more than Rs. 6,600 Cr. for three projects - to develop the second phase of Chennai Metro, to help India on Sustainable Development Goals (SDGs) and for a dairy project.
- The present year news articles highlight how the country's remarkable progress is accelerated in moving towards achieving Sustainable Development Goals. UN officials expressed "awe" over this situation of the country.

- It has been noticed that, among all the news covered, biodiversity, wildlife and overall environment is hardly anywhere in the picture. The only news article about wildlife was about increase in the number of tiger population from 1,411 in 2006 to 2,967 in 2019.

- India's green governance, new policies or decisions (both positive and negative) which are of paramount importance to tackle the key issues of SDGs are not much highlighted in the news.

\section{D. $\mathrm{CNN}-18$}

The search found approximately 62-65 news under the heading of 'Sustainability News' on this channel. Out of these articles, only 35-40 were found to be actually relevant for this study. Hence the following annotations can be drawn.

- One of the articles from 2015 has spoken about the 'Up in Smoke report' (about impacts of climate change) and 'Bloomberg report' (about small-scale renewable energy options) and its connection to achieve SDGs.

- There is noteworthy news which mentions that, the transport sector is the second largest contributor to GHG emissions in India giving the accurate numbers of carbon emission in the news article.

- One more 'must mention' article is about integrating holistic risk management in sustainable development. It states that, risk management can no longer remain fragmented, but must be considered in its totality. The global initiatives like - International Decade for Natural Disaster Reduction (IDNDR), Yakohama Strategy and Hyogo Framework are also addressed separately in this article.

- This can be noted that, unlike the other channels studied, $\mathrm{CNN}-18$ has incorporated various contemporary issues.

- 2016 News articles mostly talk about the comments, opinions or expressions by the politicians like PM Narendra Modi, Kailash Satyarthi, Abdul Kalam and UN Secretary-General Ban Ki-moon about various different topics related to SDGs.

- A very unique subject was touched upon by this channel in the mid of 2017. Fashion industry in India is emerging with a new branch as 'Sustainable Fashion' or 'Ecofriendly fashion'. Many renowned fashion designers talked about this concept in 'Textiles India 2017'- the first ever global B2B textiles event in India. They announced that 'Sustainability is the future and textile is at the heart of it'. The old pieces of fabric which are the memories of our heritage are sourced and restored. The vintage textile is fortified with man-made yarns and moulded into relevant runway designs; thus its lifespan is extended.

- Some articles focus on the technological advance of the country in combating the issue of climate change and GHG emission. The government's financial support to carbon-capture technology is one of them. On the similar lines, the success of Tesla's electric cars and Volvo's Electrification Program which received recognition From United Nations is also mentioned thoroughly. 
- An article about the initiative taken by the big names in the Automobile Industry is worth mentioning here. BMW Group, (Mercedes-Benz parent company) Daimler, Ford, Honda, Jaguar Land Rover, Toyota Europe, the Volkswagen Group and Volvo have joined forces to reduce its supply chain's environmental impact [21] so as to reduce its dependency on it through greater recycling of materials.

- The coverage of 'Science for Water' conference convened by UNESCO and Joint Research Centre of the European Commission by the channel in February, 2018 is quite remarkable. Though it is in sync with SDGs, hardly any news channel spoke about it.

- 'Bill Gates' collaboration with the Japan Sports Agency in an effort to achieve the United Nations' Sustainable Development Goals (SDGs)- that is the launch of 'Our Global Goals' partnership by publicising them through the Tokyo 2020 Olympics'[22] is also big international news which was not observed at the international news channels but mentioned by CNN-18 in November, 2018.

- Only one news article among all has coverage of the world's protected areas which are experiencing major shortfalls in staffing and resources and are therefore failing on a massive scale to safeguard wildlife and biodiversity. No much focus is given to the wildlife or biodiversity issues.

\section{RESULTS AND DISCUSSION}

The analysis of four news channel websites for the time span of 4 years to identify the news coverage on the Sustainable Development Goals (SDGs) has resulted as follows:

- Indian news channels have covered more relevant news than the global channels with regard to SDGs. Even the global incidents which are of prime importance are not much considered by the global channels.

- BBC and Al Jazeera seemed to have more inclination towards the African countries and their achievement in meeting SDG targets. Whereas there is not much focus on other countries and their advancement (technological or economic) is hardly noticed.

- Almost all the channels cover the news related to political entities and their expressions on various situations. The work of social groups, public trusts or NGOs which work genuinely towards minimizing the problems of hunger, poverty and illiteracy are not at all taken into account.

- As observed, none of the studied websites touch upon the global goals other than Hunger, Poverty, and Education and to some extent Climate action. The other goals which are truly essential to be covered like Gender Equality, Industry-Innovation and Infrastructure, Responsible Consumption and Production are not much highlighted.

- Coverage of issues like Biodiversity degradation and Wildlife habitat fragmentation is negligible in all the channels.

- New ideas/ innovations/ techniques to improve the economic situation of the countries and to meet the target by 2030 are spoken out only by CNN-18. Rather, this channel has highest number of topics covered under the title of Sustainability- those having aspects of both national and international importance.

\section{CONCLUSION}

It can be concluded that, Indian News media is not lagging behind the International one in case of covering the news related to SDGs and making people aware of it. Rather, Indian news channels show comprehensive approach towards this. The study was limited to 4 news channels through their websites and for the period of four years and only highlighting the SDGs. This work can be extended with more News channels' websites (both national and international) and for larger time span. Further quantitative and comparative study can be done to measure the reach of news related to SDGs to the intended audience and actions resulting out of the coverage.

\section{ACKNOWLEDGMENT}

The author is thankful to Adv. Gouri Joshi and Prof. Mochish KS for their valuable inputs and guidance for this paper. Also, thanks to Mr. Manish Joshi for the constant support and encouragement during the entire process of this research.

\section{REFERENCES}

1. https://onlinelibrary.wiley.com/doi/pdf/10.1002/9781444395433

2. Gesa Luedecke, Maxwell T. Boykoff. "Environment and the Media", Wiley, 2017

3. https://sdgintegration.undp.org UNDP official website

4. http://www.cmsenvis.nic.in/qnewsletter/Apr-to-June-2014.pdf

5. Matthew S. VanDyke, John C. Tedesco. "Understanding Green Content Strategies: An Analysis of Environmental Advertising Frames From 1990 to 2010", International Journal of Strategic Communication, 2016

6. https://www.internationalhispanicmedia.org/el-ambiente-y-lasnoticias-understanding-u-s-spanish-language-newsrooms-coverageof-environmental-issues/

7. https://sustainabledevelopment.un.org/?menu=1300

8. https://postcourier.com.pg/zero-progress-school-places-decade-un/

9. https://www.bbc.com/news/business-41149083

10. https://www.bbc.com/news/world-35370021

11. https://www.bbc.com/aboutthebbc/reports/policies/sustainability

12. https://afrimasterweb.com/home/african-news/nigerianews/news/foreign/bad-governments-cannot-meet-un-goals-obama

13. https://www.aljazeera.com/amp/news/2015/10/bolivia-moralesblames-capitalism-climate-change-151013084626123.html

14. http://worldnewsnetwork.co.in/blue-economies-growth-throughhumanitys-relationship-with-water/

15. https://www.aljazeera.com/news/2019/10/world-food-day-fight-foodwaste-191016120808684.html

16. https://www.aljazeera.com/programmes/planet-sos/

17. http://www.ndtv.com/india-news/kailash-satyarthi-calls-for-childrelated-sustainable-development-goals-at-un-summit1223308 ?ndtv_related=

18. https://sustainabilitynext.in/category/news/page/4/

19. http://m.ndtv.com/india-news/india-will-be-late-by-50-years-inachieving-education-goals-unesco- 1454898

20. https://www.dailypioneer.com/2018/india-abroad/india-s-success-in2030-un-sdgs-can-change-face-of-the-world--unga-president.html

21. http://motoring.iafrica.com/newsbriefs/1057090.html

22. https://www.news18.com/newstopics/bill-gates.html

\section{AUTHOR'S PROFILE}

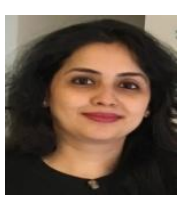

Ms Swamini Pandit is a visiting faculty at SP Pune University at the Department of Environmental Science for the past four years and at Flame University. The overall experience in teaching is more than 10 years. Her specialisation is in Environmental Law from NLSIU, Bangalore. She has a keen interest in environmental governance, global goals' development and environmental awareness throughmedia. 